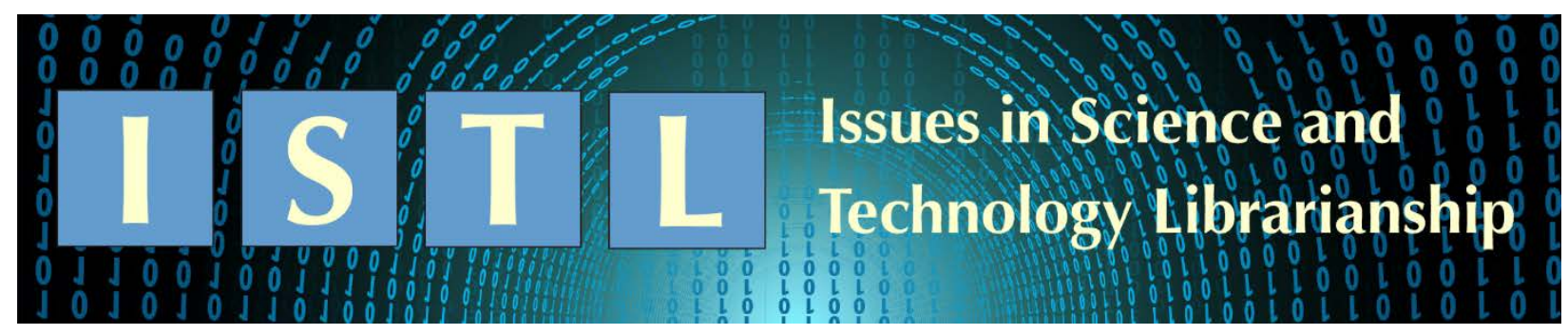

\title{
Information Literacy Strategies Used by Second- and Third- Year Biology Students
}

\author{
Catherine Lantz \\ Reference and Liaison Librarian \\ clantz@uic.edu \\ Paula R. Dempsey \\ Head Librarian, Research Services \& Resources \\ dempseyp@uic.edu \\ Richard J. Daley Library \\ University of Illinois at Chicago \\ Chicago, Illinois
}

\begin{abstract}
Results from focus groups with 23 second- and third-year biology students revealed gradual gains in information literacy (IL) abilities and dispositions needed for them to join the community of scientific practice as laid out in the ACRL Framework for Information Literacy for Higher Education. Students were consumers of information and not yet producers of information. They interacted often with primary research articles but struggled to use research tools effectively; remembered active learning vividly; and relied on video resources, Google, and discussions with peers and instructors to define terms and understand results. Findings support the value of collaboration between librarians and science faculty to incorporate IL skills in the process of scientific discovery.
\end{abstract}

\section{Introduction}

Second- and third-year science students are often at the crossroads of consuming information and producing research, as they apply learned content and procedures to scientific inquiry. Joining the community of scientific practice requires confident use of information in all formats (Elrod \& Somerville 2007). Therefore,

[t]he ideal biology curriculum would teach students that discovery at the bench or in the field is dependent on existing knowledge and literature; likewise, discovery is only valuable when it becomes part of the literature and the body of knowledge in a field by way of literature or other communications (Winterman 2009).

This idea is developed in the ACRL Framework for Information Literacy for Higher Education, which proposes six conceptual frames for the ways in which students develop abilities to discover, analyze, and use information in communities of learning (Association of College \& 
Research Libraries 2015). Many studies have examined how curricula address the skills, practices, and dispositions necessary to become an information-literate scientist. We have not identified any study that examines science student perceptions about the extent to which and in what ways second- and third-year students learn to think like scientists about information. Using focus groups, this study addressed the following research questions for students at UIC:

- What memories do students retain about information literacy (IL) instruction in introductory biology in their second and third years of college?

- What IL skills and dispositions do second- and third-year students practice as they progress in biology?

- From whom and in what fashion did they learn these skills?

- What gaps remain in their approach to science literacy and IL?

Classes taught in the Biological Sciences department at the University of Illinois at Chicago (UIC) support more than 2,500 students in four majors: B.S. in Biological Sciences, B.S. in Biochemistry, B.S. in Neuroscience, and B.S. in Integrated Health Studies. An introductory lab in information literacy in BIOS 101 is taught by course instructors, rather than librarians. Biological Sciences 220 is a required course for three of the four majors (and one concentration), and it is recommended that students take it in their second or third year. For this study, researchers recruited students from BIOS 220 to share their experiences with IL in three focus groups. Understanding their point of view is important for expanding and improving IL instruction and building library services and collections that allow students to continue on the path to becoming expert users of the literature in their field.

\section{Literature Review}

Expectations for science students' IL include both the broad concepts in the ACRL Framework and the specific abilities in the Information Literacy Standards for Science and Engineering/Technology (Association of College \& Research Libraries 2006). Researchers in library and information science have investigated many options for integrating information literacy (IL) and scientific literacy (SL) in the biology curriculum, most at the first-year (100) level (Fuselier \& Nelson 2011; Gregory 2013; Jacklin \& Robinson 2013; Hartman et al. 2015). Instruction in IL for introductory biology is often a collaboration between librarian, science faculty, and graduate teaching assistants (Elrod \& Somerville 2007; Winterman 2009; Porter et al. 2010; Miller 2011; Hartman et al. 2015; Lantz 2016).

Most of the research cited above is limited to describing the pedagogy and noting how students and faculty respond during and immediately after IL instruction. Follow-up studies are important to explore what students remember about this instruction and how they put it to use as they advance in their biological studies. Dinkelman (2010) analyzed syllabi for courses required for a biology major and found that few IL assignments were included in coursework, with the most common assignment being a lab report or exercise. As Porter et al. (2010) note, "while an early exposure to IL and SL skills is important, equally important is the continued, progressive development of these skills across the curriculum." Our study contributes findings about how students recollect and employ what they learned in foundational IL and SL experiences later in their academic careers.

Perry (2017) interviewed 18 science faculty members to discover their expectations of student research skills and learned that faculty were most concerned with students' ability to identify and 
work with primary research, although many also assigned or recommended secondary resources in the first year of study:

They recommended that the students begin with secondary sources, their textbooks, and even Wikipedia to become familiar with the topic before moving on to more sophisticated research. Respondents stated that they wanted students to understand that different literature serves different purposes. One said s/he wanted students to "use research to expand their knowledge and find new references." Faculty wanted students to focus on literature they could understand, and that they could relate to what they are doing in the classroom.

Two studies identified baseline understandings of how much and what kinds of research faculty expect of students in the biological sciences (Dinkelman 2010) and how students perceive their own IL skills and use of information (Ferguson et al. 2006). Molteni and Chan (2015) found that upper-level health sciences students were over-confident in their abilities to complete research tasks. Blank et al. (2016) developed an assessment tool to compare IL skills of first-year and senior biology students and found that seniors had stronger skills in searching peer-reviewed literature, citing articles correctly, and answering other questions about scientific literature correctly. They found that students with senior-level standing were more likely to find "relevant, peer-reviewed journal articles, provide appropriate citations, and provide correct answers to other questions about scientific literature," and first-year students and seniors also indicated different levels of training with such skills.

Callinan (2005) surveyed first- and final-year biology students to compare their use of library space, collections, and staff. They found low use of subject-specific databases, although higher among upper-level than first-year students. They also found upper-level students used more types of sources and journal articles for class assignments than do first- and second-year students. While all students in the study were more likely to ask a peer for help than a librarian, upper-level students were more likely to ask a librarian than lower-level students, and final-year students were still asking for more instruction.

Ferguson et al. (2006) found first-year students rely on web resources, have difficulty evaluating and citing different types of sources and generally overestimate their searching abilities. Both Ferguson and Callinan commented on the lack of research done on undergraduate users in specific disciplines with respect to their year of study.

Our study contributes evidence of how students in their second and third years articulate their place on the trajectory of IL and SL skills, preferred learning strategies, and growing acculturation in the scientific community.

\section{Methods}

We used focus groups to elicit students' genuine understanding of IL, because this method is an effective way to encourage participants to present their experiences in ways that are meaningful to peers (rather than relating what participants imagine the researchers want to hear). Focusgroup discussions are also noted for prompting memories for other participants and allowing participants to modify and extend one another's ideas (Morgan \& Krueger 1993).

Building on a previous study (Lantz 2016) of how first-year biology students learn IL in BIOS 101, Biology of Populations and Communities, we targeted students in BIOS 220 for this study. 
BIOS 220 is a core course for majors that has BIOS 101 as a prerequisite. BIOS 220, Mendelian and Molecular Genetics, is known as a difficult course; some students save it until their fourth year to make sure they can do well in it. Thus, this population of second- and third-year students is not typical of students at the institution or of science students in general, but rather represents a successful group of students who chose to attempt a challenging course earlier than others. This purposive sample, excluding final-year students, is appropriate to explore the experience of inbetween students, whose experience has not previously been studied.

The course had 375 students in spring semester 2017. At the request of the researchers, the course instructor emailed students and posted a notice about the study on the course web site. An original incentive of $\$ 25$ did not draw enough volunteers, so it was raised to $\$ 50$. The higher incentive filled the available slots for three focus groups and provided a waiting list. All but one student who signed up participated in the focus groups. The incentive might have appealed more to students with limited resources, but there is no evidence in the data to suggest that was the case. Holding the groups on Monday, Wednesday, and Friday excluded students who have a class at noon on those days, but it did not systematically exclude any demographic group. In a paper survey students completed before the conversations, they reported how many semesters they had attended UIC, when they had taken BIOS 101, whether they had received library instruction and in which course(s), and their aspirations for graduate degrees and career field (see Table 1). There was no intention of generalizing to the population, but rather to fully explore variations in successful students' experience.

Table 1. Characteristics of focus group participants $(n=23)$

\begin{tabular}{|c|c|c|c|c|c|}
\hline Major & Biology: 13 & Biology/psychology: 3 & $\begin{array}{l}\text { Bioengineering: } \\
2\end{array}$ & $\begin{array}{l}\text { Biochemistry: } \\
2\end{array}$ & $\begin{array}{l}\text { Not } \\
\text { stated: } \\
3\end{array}$ \\
\hline $\begin{array}{l}\text { Library } \\
\text { instruction } \\
\text { included in } \\
\text { course }\end{array}$ & $\begin{array}{l}\text { First-year } \\
\text { writing } \\
\text { (FYW): } 15\end{array}$ & $\begin{array}{l}\text { FYW and an } \\
\text { additional course: } 3\end{array}$ & Biology 101: 1 & $\begin{array}{l}\text { None/not } \\
\text { sure: } 4\end{array}$ & \\
\hline $\begin{array}{l}\text { Semesters } \\
\text { at UIC }\end{array}$ & $\begin{array}{l}7 \text { or more } \\
\text { semesters } \\
\text { (including } \\
\text { summers): } 2\end{array}$ & 5 or 6 semesters: 8 & $\begin{array}{l}3 \text { or } 4 \\
\text { semesters: } 7\end{array}$ & $\begin{array}{l}1 \text { or } 2 \\
\text { semesters: } 4\end{array}$ & $\begin{array}{l}\text { Not } \\
\text { stated: } \\
2\end{array}$ \\
\hline $\begin{array}{l}\text { Semester } \\
\text { taken } \\
\text { BIOS } 101\end{array}$ & $\begin{array}{l}\text { Fall 2014 / } \\
\text { Spring 2015: } \\
6\end{array}$ & $\begin{array}{l}\text { Fall 2015 / Spring } \\
\text { 2016: } 5\end{array}$ & Fall 2016: 4 & $\begin{array}{l}\text { Not taken at } \\
\text { UIC: } 7\end{array}$ & $\begin{array}{l}\text { Not } \\
\text { stated: } \\
1\end{array}$ \\
\hline $\begin{array}{l}\text { Graduate } \\
\text { degree plan }\end{array}$ & $\begin{array}{l}\text { Medicine } \\
\text { and/or } \\
\text { neuroscience: } \\
8\end{array}$ & $\begin{array}{l}\text { Dentistry, optometry, } \\
\text { pharmacy, health } \\
\text { sciences: } 7\end{array}$ & $\begin{array}{l}\text { Biology or } \\
\text { biochemistry: } 6\end{array}$ & $\begin{array}{l}\text { Engineering: } \\
1\end{array}$ & $\begin{array}{l}\text { Not } \\
\text { stated: } \\
1\end{array}$ \\
\hline $\begin{array}{l}\text { Career } \\
\text { plan }\end{array}$ & Physician: 11 & $\begin{array}{l}\text { Health sciences } \\
\text { practitioner (e.g., } \\
\text { nurse, lab technician), } \\
\text { pharmacist, }\end{array}$ & $\begin{array}{l}\text { Research } \\
\text { scientist: } 1\end{array}$ & Author: 1 & $\begin{array}{l}\text { Not } \\
\text { stated: } \\
1\end{array}$ \\
\hline
\end{tabular}




\begin{tabular}{|l|l|l|l|l|}
\hline & $\begin{array}{l}\text { orthodontist, } \\
\text { optometrist, dentist: } 9\end{array}$ & & \\
\hline $\begin{array}{l}\text { Note: Students included } 13 \text { women and ten men; women spoke slightly more than men, on average } 838 \text { words per } \\
\text { woman and } 757 \text { words per man. }\end{array}$ \\
\hline
\end{tabular}

The Institutional Review Board approved the study as exempt because no identifying information was gathered in the audiotaped conversations; students identified themselves with an assigned letter of the alphabet. The researchers hired a third party to transcribe the sound files and destroyed the files after reviewing the transcriptions for completeness and accuracy. Transcriptions are complete but not verbatim (i.e., the transcriber did not record pauses, stumbles, or laughter). Quotations from the conversations are not corrected for grammar, but overuse of like was omitted.

The second author moderated the focus group interviews. The moderator had graduate training in conducting focus groups but had not previously conducted focus groups on her own. The moderator had no science background, and she announced this at the beginning of each session to explain why she might need students to clarify or elaborate. See appendix for the focus group script.

Analysis of the data began with open coding, each researcher viewing the data individually through two different lenses, by speaker and by question, to consider the student narratives as a whole, as well as themes across students. The next step was low-inference coding to identify which categories of people, kinds of resources, and activities students mentioned. In the next step, each author wrote memos about each activity: Searching, Reading, Modeling, Citing, Discussing, Doing, and Evaluating. The memos were open-ended "thinking aloud" about the emerging themes in the text. Next the authors exchanged memos and responded to the ideas by seeking discrepant examples and alternative explanations (Groenewald 2008). The goal was not strict objectivity, but rather transparent reflection and systematic questioning of preconceptions. Because one author had familiarity with scientific concepts and the science curriculum and the other did not, their complementary viewpoints balanced the interpretation.

There are at least two ways the method could be improved. First, although the moderator used her outsider/naive status at some points to deepen the conversation, at other points she let complexity slide. For example, when a student was struggling to explain "quality versus quantity" and asked "you know what I mean?" the moderator agreed rather than saying "I think so, but please say more about that." Second, because of time constraints on the researchers (the best time in the semester to host focus groups was the busiest instruction time for the library), researchers did not formally debrief after each focus group to compare immediate impressions. It might have made for richer interpretation to clarify and extend the analysis while the discussions were still fresh.

\section{Results and Discussion}

Conversations with second- and third-year students revealed several strategies students had developed for finding and interpreting scientific information. Students did not explicitly refer to either information literacy or science literacy in the focus groups, but their discussion of skills and resources included both concepts. Of the 23 students in the focus groups, eight students recounted memories of the BIOS 101 lab session that centered on IL and database searching, and 15 students did not. (Five of these students were transfer students who had not taken BIOS 101 at 
UIC.) The BIOS 101 lab on IL occurred early in the course and included an activity and discussion on finding and reading primary research articles. A follow-up activity later in the semester involved students presenting in groups on a primary research article. It was not possible to know which comments came from second-year students and which came from third-year students, because survey responses were not associated with students' coded identities in the focus groups. Although ten students who had taken BIOS 101 did not share memories of the lab, it does not mean they had no recollection of it.

To various degrees, students described encountering and sometimes moving across thresholds outlined in the ACRL Framework for Information Literacy for Higher Education (Association of College \& Research Libraries 2015). Some of the concepts that students mentioned were specifically related to being socialized in the use of scientific information and others were more general.

\section{Searching as Strategic Exploration}

When talking about searching, students mentioned a number of specific databases, periodicals, and web sites. They showed a range of awareness of the value of specific resources for meeting their needs, but they seemed to struggle with unfamiliar interfaces and defaulted to what was familiar:

So, it was difficult trying to navigate the format of how to search everything. And I usually do get my journal articles from JSTOR, only because I'm familiar with it and I feel like it's much more easier to use. ... And I'm more familiar with it because I've used it in high school.

Students who relied on JSTOR might be missing the most current scientific findings, because JSTOR does not include the most recent five years for most journals. Students usually mentioned only key-word searching. More sophisticated options were unusual. One student "was just confused on where to start, so I just had to type in the key words." The more advanced search options that students mentioned included searching by author (to find articles by a research mentor), following cited sources, Boolean operators, phrase searching, and limiting by time period for more current research. Students talked about narrowing searches and much less frequently about broadening them. They were more likely to give up or to settle for a less than ideal resource than to ask for assistance. One student talked about a research mentor providing a relevant article or specifying a journal title to "better help me narrow down my searches." Another preferred JSTOR because "I feel like it’s easy to narrow down your choice.” Not all students appeared to be familiar with options for narrowing a search, and they reported spending a great deal of time sorting through results.

\section{Authority Is Constructed and Contextual}

Students related experiences that show they had begun the process of constructing hierarchies of trust regarding research tools, sources, and advisors. Table 2 shows that students mentioned a wide range of information resources and tools. Most often discussed were journal articles and then databases, with web sites, periodicals, and citation managers a distant third. Students talked about the comparative value of databases, depending on where they were in the search process or what they needed to find. One student mentioned that BIOS 101 instructors encouraged them to go beyond JSTOR to "specifically science databases ... I'm pretty sure there was Science, 
Nature,” conflating databases with science periodicals. One student mentioned consulting “even a librarian" to learn which databases to use.

I think our TA recommended I use Science a lot, 'cause she said that was one of the higher, like the ones that they use a lot in research, and Nature.

I would go to Google because I wasn’t looking for a scholarly article, and I would google it and see what's the latest research.

I tried to use Google Scholar, but I did not find that useful because when you don't know what you are looking for, Google Scholar is not the best option.

I actually learned in my English class how to find scientific articles here, in [firstyear composition]. ... So from then on, that was my first semester here, freshman year, I always used the Science Citation Index. And that's always been really reliable for me.

I get access to so much more information through UIC's specific database, and that's a life saver. Plus as someone who really might not know we even have that, but just relies solely on Google, I think that's ... But all of us, since taking science classes here, we know about the database, so I think that's my number one most useful thing for writing papers and look up papers.

Socialization into a scientific community of practice is evident in several of these comments. For example, the student who refers to Science Citation Index most likely learned to call it that from a more experienced science researcher; the library web site lists it as Web of Science. In the prior quotation, the student implies that because science students know about library resources, they are more informed than "someone who ... just relies solely on Google.” Given the vague reference to what is most likely the library's discovery system, Summon, the student is still making progress toward full information literacy.

Table 2. Resources mentioned in focus groups

\begin{tabular}{|l|l|l|l|}
\hline Resource type & $\begin{array}{l}\text { Number of } \\
\text { students }\end{array}$ & $\begin{array}{l}\text { Number of } \\
\text { mentions }\end{array}$ & Specific mentions \\
\hline Articles/papers & 19 & 90 & \\
\hline Citation tools & 10 & 16 & $\begin{array}{l}\text { Citethisforme.com (formerly RefME), Easybib, } \\
\text { MS Word }\end{array}$ \\
\hline Databases & 21 & 85 & $\begin{array}{l}\text { EBSCOhost, Google ("obviously it's a } \\
\text { database"), Google Scholar, JSTOR, Lynda.com, } \\
\text { PsychInfo, PubMed, Science Citation Index }\end{array}$ \\
\hline Dictionaries & 1 & 1 & Dictionary.com \\
\hline Encyclopedias & 4 & 8 & Wikipedia \\
\hline Institutions & 1 & 1 & NIH \\
\hline Mass Media & 3 & 4 & ABC News, NPR, This American Life, TED \\
\hline Periodicals & 10 & 24 & $\begin{array}{l}\text { Annals of Emergency Medicine, Cancer, Nature, } \\
\text { New York Times, Science, Time, Washington } \\
\text { Post }\end{array}$ \\
\hline
\end{tabular}




\begin{tabular}{|l|l|l|l|}
\hline Social Media & 2 & 3 & FaceBook \\
\hline Textbooks & 3 & 4 & \\
\hline Videos & 8 & 22 & AK Lectures, Khan Academy, YouTube \\
\hline Web sites & 11 & 15 & $\begin{array}{l}\text { Packback.co, Protein Bank, Purdue OWL, } \\
\text { Pymol, SciShow News, Yahoo News }\end{array}$ \\
\hline
\end{tabular}

Students made some evaluation distinctions in reading about science online. Most differentiated between news stories and scientific articles, but they rarely paid attention to the specific news source. Across the entire group of students, there was a hierarchy of sites that they mentioned as being less credible or appropriate for academic purposes, such as Wikipedia and Facebook. However, some of the sites lower in the hierarchy were mentioned uncritically by other students. Students mentioned a range of criteria for evaluating the worth and/or applicability to their research project, such as:

- The reputation of the source: In order of increasing credibility, they mentioned Facebook, Google Scholar, PubMed, and "big name” journals. One mentioned that relying on an .edu site would be sufficient in a "worst case scenario" when they could not find a citation.

- Citations: Students recognized the meaning of high citation rates as an indication of both influence on the field and lack of currency: "... articles that have been cited like 100 plus times, sometimes a TA would tell you avoid those, or maybe go for those, depending on if you want to talk about new information. ... So either it's like knowledge or research that is new to the field, so it might be cited maybe only a few times, but if it's an older article from the " 90 s or something it might be cited like 500 times."

- Limitations: Author-identified limitations in studies guided students in evaluation: "the research will be good, but they won't have this definitive finding where it's like oh yes, this is completely related to X, Y, you know. It'll just be like yeah, there's just a little correspondence or correlation in between these two things, so it's like, okay. So then you trying to consider the limitations of the research I think is really important because then the people know the shortcomings of their research. And you can kind of, I guess, judge how good the research was and what they actually found from it from their limitations."

- Bias/sensationalism: Students found that popular presentations of scientific studies showed signs of bias or oversimplification that could tend to sensationalize findings: "In a scientific article they show you what could have happened wrong, but in a simplified article they will just tell you oh, that was the result, and that was what we were aiming for."

- Relevance: Identifying articles that related to their topics sometimes led students to studies on broader or narrower aspects. They recognized that grasping the gist of the argument was vital: "So I've learned over the years that if you're going to cite someone, make sure that they're supporting your argument. Because you might cite someone who looks like, it's cherry picking, where you just pick something out, oh, this looks like it'll support my argument, but the actual author's point of view isn't anything like compared to yours. So you want to be sure that the author is actually supporting your viewpoint."

\section{Information Has Value}


Students reported a range of behaviors and attitudes towards citing previous research. There is a spectrum of belief from those who believe not doing it will get them "kicked out of school," to those who think it is only fair to authors to give them credit, to those who have internalized a scientific perspective that documentation is central to establishing facts and furthering science.

In terms of formatting citations, there is also a spectrum of skill from those who report continuing to struggle, those who look for citations provided online, those relying on generators and not understanding the concepts, those who use the generators and understand the concepts enough to "make sure I have everything perfect," and those who are learning the skill or have already internalized it. Students reported learning citation from TAs, high school librarians, peers, websites, and professors. Others reported feeling lost:

It kind of sucks because TAs automatically assume that we know how to cite sources, so I feel a bit more discouraged to ask them, because they more have like, oh, hey, just cite it, you should know, you're in college, you're an adult. But in reality, I have no idea how to cite sources. So I tend to not go to them and ask because I don't want to seem like I'm dumb ...

Students reported that many professors and TAs did not care about citation style, "just use whatever, and just stick to it," while others were intent on the "little pedantics," such as where to use commas. Some found their high school teachers were pickier, while others found that these details were more important in college.

While students in this study saw the value of giving credit, they had mixed feelings about citation styles and the process of citing accurately. Other researchers support this finding of increasing awareness but lack of specific skills regarding citation (Blank et al. 2016). Citation is, therefore, a logical topic to include in librarian-led instruction. Citation connects all parts of the research cycle, and giving credit is an essential tenet of IL instruction.

\section{Scholarship as Conversation}

In reflecting on their engagement with scientific literature, students focused on the difficulty of reading primary research articles; only one discussed a strategy for contributing to that conversation, and that was gained in a composition course rather than a science course:

So it's actually just things I learned in English and modifying that for a science paper, you know, writing an outline and having that figured out before you start writing, and just start filling in the pieces rather than just finding the articles and trying to push it together. More like making it fit into something that you already have an idea about.

This reflects the student working to contribute a point of view, rather than patching together ideas from various sources. Strategies for dealing with academic language included finding a simplified report on the study in secondary news sources, watching videos, looking up definitions online, asking someone (a peer or, in one case, a sister with a master's in biology), putting a new concept in context with something they already know, and looking up cited articles in hopes of finding more background.

There's a lot of scientific terms that I'm just not familiar with, so I do have to just do, like continue my research and do sidetrack research as well. 
Students also reported strategies for digesting scientific articles. They heard from faculty that analyzing articles and synthesizing concepts are transferable skills and therefore worth the effort to master. They connected critical thinking with reading an article and understanding it, but, perhaps, not with the skills to find and evaluate it.

I usually start with the abstract and make bullet points and try to find okay, where do they talk about this and try to find it in the article.

So what I typically do is I look at each of the figures and then go back to the article to define some of the words in the figures, because the figures are basically a summary of the information they're presenting at that point in the article.

... I remember [a Science Learning Center tutor] read both of those paragraphs and then he quickly went and skimmed through the tables that they had and he got the whole gist of the article from the tables and was able to break it down. So that's something I learned, like if I'm...if I don't have a lot of time on my hands I can just quickly skim.

Some people would just go in-depth, like read it like a novel. And I was told you're not supposed to do that. You're supposed to understand the abstract first of all. That's the whole summary of everything. And then look at the introduction. Then you can look at the methods and the results will show the graphs, so you should just look at the graphs, mostly, because the results just explain the graphs. And then look at the discussion, just skim through it and see what the null hypothesis is and things like that.

Thus, most students learned ways to reduce reading time, but one student was advised to take more time:

My TA always tells me to read it more than once. ... Not just like skim it through and like oh, I have the gist. No, you probably don't. ... Always try to get feedback to make sure you're understanding it correctly.

Students identified discussion as a significant learning technique. Discussions they mentioned were on topics ranging from big issues in science to a tip about a useful citation generator. Discussions were both formal (in class) and informal (with friends outside of class):

So what was interesting is that, my friend was doing the results, and when I read her slides it was like oh, that's not what I understood from the results. So we were kind of like discussing.

We each one of us understood the experience in a different way. So we went to the reference page and we tried to see what did they list on their references and see if we can find any related research that would kind of like understand it.

Students also identified listening in to someone else's discussion (e.g., YouTube videos) as a helpful way to learn.

I’ve never been told to look up YouTube videos, really, but I feel like watching YouTube videos gives you just a second perspective, or learning it twice, maybe learning it a different way. For some people it might be an easier way to learn it.

It was easier to understand when you saw the visual aspect of it rather than just reading it. 
... reading it generally is more tied to memorizing the information, whereas

understanding how it's done [from watching a video] helps recall the idea better.

Students who had a strong memory of a learning experience connected that experience to the instructor. Engaging in conversation also built relationships in the university research community that bolstered learning. In most cases, students remembered who had taught them an important skill or concept. Each student mentioned at least one person and as many as nine people during the focus groups. Professors were mentioned most often (43 mentions), followed by teaching assistants (26), peers (10), librarians (7), research mentors and high school teachers (6 each), and tutors (2). Students reported learning many concepts from these people: finding databases, searching databases, how to read a research article, citation, and their own interest in a topic of research. Many students recalled the research interests of their TAs and professors. One student found that many TAs and professors emphasized the lifelong value of IL:

... reading a research paper and extrapolating the main details and stuff is a really huge skill that anyone and everyone can use, no matter which career you go into. You know, it just makes you into an analytical and critical thinker.

There was evidence in the focus groups that second- and third-year biology students connected enthusiastically with doing science but did not yet see themselves contributing to the scholarly conversation. Students readily recalled active learning activities from previous years and were enthusiastic about the role of active investigation in biology classes. They saw the value in it, even when it "goes wrong" or is "hard." When asked what they remembered about their first-year biology lab course, most recalled an activity such as collecting samples from a pond, identifying plants, using the microscope. Thus students talked about doing science but not about creating scientific content, only consuming it. The omission might be because they were not specifically asked about this aspect of research, or because they were not yet at that level of participation.

\section{Conclusion}

Students' learning experiences in BIOS 101 in their first year are foundational to growing their IL skills and shaping their information seeking behavior. These experiences form the base upon which a scaffolded approach to IL can be built, where skills are taught repeatedly with increasing levels of difficulty. First-year experiences set the baseline for how students develop over the next three or four years. The IL lab exercise, SL class discussion, and presentation of a primary research article activities that took place in BIOS 101 are typical of other biology programs (e.g., Dinkelman 2010).

Though students had used and built on the skills covered in the introductory BIOS 101 lab, they themselves did not see the IL lab as a starting point of their exposure to information literacy. The BIOS 101 lab was, for many, the first time they had used an academic database in a science class in college, but they bring prior experience searching for and evaluating information, for example, from their high school coursework. Therefore, it is logical that students did not easily recall the first lab of the class as about finding scientific literature -- it was not an important first for them. Also, students didn't talk about finding, evaluating, and reading articles in the same terms or enthusiasm as they did with the in-lab activities. Even when one of the labs included looking at classified ads online, this activity was seen as 'collecting data,' rather than as an information activity. Though many IL activities are purposely inquiry-based or incorporate active learning components, they were not as memorable as the other laboratory activities students related. 
Mid-career student reliance on a mix of resources (scholarly and unscholarly) indicates movement towards, but not a full embrace of, academic literature. Our findings that students still use general search engines on the open web even though they are aware of other databases agree with Shanahan's (2008) results. Students in our study reported using secondary sources to help make sense of primary articles. While Google is "search engine of choice" both pre- and postintervention in the Shanahan study, and, in our focus groups 14 students mentioned Google, we also found that students use both Google and library databases for their searching. Students in this study mentioned six different topics they would have liked to learn earlier in their studies, including how to read scientific articles, proper citation, and selecting databases.

We believe effective IL pedagogy needs to be tailored not just to the course, but also to students' experiences, skills, and knowledge. Our future work will target graduating seniors in Biological Sciences to further inform our timing of information literacy skills instruction. Specific practices based on these focus-group findings have not yet been implemented at UIC, but better understanding of how second- and third-year students think point to some potential interventions:

- In courses where course faculty cover information literacy, rather than librarians, offer tutorials and/or guides to citation practices, how to read a scientific article, and how to use scientific databases.

- In sessions taught or co-taught by librarians, partner with science instructors to model IL skills as part of the process of scientific discovery. This strategy will draw on students' enthusiasm about active investigation.

- $\quad$ Provide resources for understanding scientific terminology, including visual resources that students prefer.

- Offer one-on-one or point-of-need support to transfer students and others who may have missed out on foundational concepts.

- Include citation practices in IL instruction sessions.

- Engage in curriculum mapping focused on department recommended plans of study to identify student populations in 100, 200, 300 and 400 level courses.

- Focus on pedagogical strategies of visualizing, discussing, and doing as ways of making sense of advanced concepts.

Framing existing science literature as data about the real world to be gathered, organized, and questioned will help students develop habits of mind to begin thinking like scientists. It is also crucial to talk to faculty and TAs about student progress along the skills continuum and the best ways to model "next steps" toward engaging with scientific information as a member of the scholarly community. This study demonstrated that students identify with scientists, but they also learn from librarians.

\section{Acknowledgements}

The authors gratefully acknowledge the generous support of the University Library Research Fund, University of Illinois at Chicago.

\section{References}

Association of College \& Research Libraries. 2015. Framework for information literacy for higher education. Chicago: American Library Association. [Cited 2018 Sep 6]. Available from http://www.ala.org/acrl/standards/ilframework. 
Association of College \& Research Libraries. 2006. Information literacy standards for science and engineering/technology. Chicago: American Library Association. [Cited 2018 Sep 6]. Available from http://www.ala.org/acrl/standards/infolitscitech .

Blank, J.M., McGaughey, K.J., Keeling, E.L., Thorp, K.L., Shannon, C.C. \& Scaramozzino J.M. 2016. A novel assessment tool for quantitative evaluation of science literature search performance: application to first-year and senior undergraduate biology majors. College \& Research Libraries 77(6):682-702. DOI: 10.5860/crl.77.6.682.

Callinan, J.E. 2005. Information-seeking behaviour of undergraduate biology students: a comparative analysis of first year and final year students in University College Dublin. Library Review 54(2):86-99. DOI: 10.1108/00242530510583039.

Dinkelman, A.L. 2010. Using course syllabi to assess research expectations of biology majors: implications for further development of information literacy skills in the curriculum. Issues in Science and Technology Librarianship 60. DOI: : 10.5062/F49Z92TJ .

Elrod, S.L. \& Somerville M.M. 2007. Literature-based scientific learning: a collaboration model. Journal of Academic Librarianship 33(6):684-691. DOI: 10.1016/j.acalib.2007.09.007.

Ferguson, J.E., Neely, T.Y. \& Sullivan, K. 2006. A baseline information literacy assessment of biology students. Reference and User Services Quarterly 46(2):61-71. DOI:

10.5860/rusq.46n2.61.

Fuselier, L. \& Nelson, B. 2011. A test of the efficacy of an information literacy lesson in an introductory biology laboratory course with a strong science-writing component. Science and Technology Libraries 30(1):58-75. DOI: 10.1080/0194262X.2011.547101.

Gregory, K. 2013. Laboratory logistics: strategies for integrating information literacy instruction into science laboratory classes. Issues in Science and Technology Librarianship 74. DOI: 10.5062/F49G5JSJ.

Groenewald, T. 2008. Memos and memoing. In: Given, L., editor. The SAGE Encyclopedia of Qualitative Research Methods. Thousand Oaks (CA): SAGE. p. 506. [Cited 2018 Sep 6]. Available from http://sk.sagepub.com/reference/research/n260.xml .

Hartman, P., Newhouse, R. \& Perry, V. 2015. Building a sustainable life science information literacy program using the train-the-trainer model. Issues in Science and Technology Librarianship 77. DOI: 10.5062/F4G15XTM.

Jacklin, M.L. \& Robinson, K. 2013. Evolution of various library instruction strategies: using student feedback to create and enhance online active learning assignments. Partnership: The Canadian Journal of Library and Information Practice and Research [Internet]. [Cited 2018 Sep 6]. 8(1):1-21. DOI: 10.21083/partnership.v8i1.2499.

Lantz, C. 2016. Information literacy in the lab: graduate teaching experiences in first-year biology. Issues in Science and Technology Librarianship 85. DOI: 10.5062/F4VD6WFV.

Miller, L.N. 2011. University biology patrons in the library literature 2000-2010: a content analysis \& literature review. Partnership: The Canadian Journal of Library and Information 
Practice and Research [Internet]. [Cited 2018 Sep 6]. 6(1). DOI:

10.21083/partnership.v6i1.1400.

Molteni, V.E. \& Chan, E.K. (2015). Student confidence/overconfidence in the research process. Journal of Academic Librarianship 41(1):2-8. DOI: 10.1016/j.acalib.2014.11.012.

Morgan, D. \& Krueger, R. 1993. When to use focus groups and why. In Morgan, D. L. SAGE Focus Editions: Successful focus groups: advancing the state of the art. Thousand Oaks (CA): SAGE Publications Ltd. p. 3-19. DOI: 10.4135/9781483349008.

Perry, H.B. 2017. Information literacy in the sciences: faculty perception of undergraduate student skill. College \& Research Libraries 78(7):964-977. DOI: 10.5860/crl.78.7.964.

Porter, J.A., Wolbach, K.C., Purzycki, C.B., Bowman, L.A., Agbada, E. \& Mostrom, A.M. 2010. Integration of information and scientific literacy: promoting literacy in undergraduates. CBE - Life Sciences Education 9(4):536-542. DOI: 10.1187/cbe.10-01-0006.

Shanahan, M.C. 2008. Transforming information search and evaluation practices of undergraduate students. International Journal of Medical Informatics 77(8):518-526. DOI: 10.1016/j.ijmedinf.2007.10.004.

Winterman, B. 2009. Building better biology undergraduates through information literacy integration. Issues in Science and Technology Librarianship 58. DOI: 10.5062/F4736NT6.

\section{Appendix}

\section{Focus Group Script}

Thank you all for being here! We appreciate your taking the time to share your experiences about finding scientific information. We asked you to join this conversation because you are 2nd and 3rd year students in Biology. We are curious about all the different experiences you have had looking for information, both positive and negative. Cathy and I are both librarians, but we're interested in much more than just the library. I do not have a science background, so I might need to ask you for additional details to make sure I understand. Also, we hope you'll talk to each other and not just me, and that you'll feel free to agree, or disagree, or give an example, and to ask each other questions. We want everyone to have a chance to talk, and so I might call on you if I'm not sure I know your perspective. We're recording the session because we don't want to miss any of your comments. We want to keep your comments confidential, and so we'll be referring to you by the letter on the card in front of you instead of your names.

Let's get started. For just the first question, let's go around the table, and start by saying the letter on your card, and then tell us about a scientific discovery you heard about recently ...

- What is a recent scientific discovery you heard about that made you curious to learn more? Where did you hear about it?

- Do you remember the lab sessions for BIOS 101? Think about your TA, think about what room it was in ... What lab activity pops into your head first?

- Do you remember the "Finding Scientific Articles Lab" during the first two weeks of class? (show page from lab notebook) What do you remember about it? What databases did you use? What did you find easiest or most difficult about it? 
- Do you remember the activity later in the semester where you presented on an article as a group? What do you remember about it? What did you find easiest or most difficult about it? Do you remember the different sections of a scientific article?

- Can anyone think of a time when someone taught you to find scientific information or other kinds of information ...was it in a classroom, or outside, who showed you? A TA? A classmate?

- Can anyone think of a time when you had to find scientific articles for another course? Did it seem easier or harder than the BIOS 101 lab? What steps did you take?

- Can anyone think of a time when you needed information but got frustrated looking for it? What happened, and how did you resolve it?

- What biology classes are you currently enrolled in? In those classes, what does your instructor or TA say about scientific literature/articles? What do they say about citing articles?

- Has anyone learned something about finding scientific articles that you wish you had known earlier? Tell us about what you learned. 